\title{
A new efficient absorption liquid to treat exhaust air loaded with toluene
}

\author{
Frédéric Heymes ${ }^{\mathrm{a}}$, Peggy Manno-Demoustier ${ }^{\mathrm{a}}$, Françoise Charbit ${ }^{\mathrm{b}}$, \\ Jean L. Fanlo ${ }^{\mathrm{a}}$, Philippe Moulin ${ }^{\mathrm{b}, *}$ \\ a LGEI, Ecole des Mines d'Alès, 6 avenue de Clavières, 30319 Alès Cedex, France \\ ${ }^{\mathrm{b}}$ LPPE, Université Paul Cézanne, Batiment Laennec, Hall C, Europole de l'arbois, BP 80, Aix en provence 13545, \\ France
}

\begin{abstract}
Volatile organic components (VOC) in the air entail health and environmental concerns. A possibility to treat industrial polluted air loaded with VOCs is absorption. In case of hydrophobic components such as toluene, poor solubility in water requires to use a specific heavy absorbent. A detailed comparison and evaluation of different kinds of organic absorbent was undertaken in purpose of toluene absorption. Four chemical classes were tested (i) polyethylene glycols, (ii) phthalates (iii) adipates and (iv) silicon oil. Experiments were performed to check gas-liquid partitioning and viscosity. Diffusion coefficients were calculated. Results showed that di(2-ethylhexyl)adipate best suits the requirements to be used as an industrial absorbent.
\end{abstract}

Keywords: Absorption; Toluene; Henry; Viscosity

\section{Introduction}

Atmospheric volatile organic compounds (VOCs) are involved in photochemical reactions creating ground-level ozone (urban smog) and entail environmental threats such as global warming, acid rains and air toxics. Although VOCs are emitted naturally, human sources are more dominant in emitting these chemicals in urban/industrialized areas. In order to reduce anthropic emissions, legislations such as Clean Air Act Amendments [1] (USA, 1990) or EEC Directives [2] (EEC, 1999, 2001) specify concentrations levels for VOCs emissions into atmosphere.

If no upstream process improvement can lead to a decrease in the VOC emission, it is necessary to setup an air treatment process. Presently, various processes are available in VOC abatements such as thermal or catalytic oxidations, adsorption, condensation, absorption, membrane permeation and biological treatments [3]. Evaluation and selection of an appropriate VOC abatement technology depends on the concentration and

\footnotetext{
* Corresponding author. Tel.: +334429085 05; fax: +33442908515 E-mail address: philippe.moulin@univ.u-3mrs.fr (P. Moulin).
}

the nature of the compounds, flow rate of the vent gas and other factors such as safety or economical considerations. But, no single method can be used in all cases: most of the methods are specific in nature.

This paper focuses on the absorption method, a simple technology for which numerous treatment equipments are available. This process presents neither fire nor explosion risk such as in thermal or catalytic oxidations and can work in sequential steps contrary to biological treatments. The key variable of this process is the choice of a suitable liquid absorbent. In case of hydrophobic VOCs, water cannot be used and other kinds of absorbents are required: water-oil emulsions [4], water-solid suspensions [5], high-boiling absorbents [6-27]. In two former cases, polyphasic nature creates homogeneity problems and parallel mass transfer resistances. Consequently, it seems more interesting to use a pure organic absorbent [5].

Several authors studied that point. An organic absorbent should have the following properties to be attractive for a industrial process: (i) a high capacity to absorb the VOC, (ii) a low viscosity and a high diffusion coefficient which controls absorption kinetics, (iii) a low vapor pressure, to reduce loss of absorbent by stripping and to prevent an unwanted air pollution 


\section{Nomenclature}

$A, B \quad$ Guzman Andrade coefficients

$C_{\mathrm{g}, \text { in }}, C_{\mathrm{g}, \text { out }}$ inlet and outlet gas concentrations $\left(\mathrm{g} \mathrm{m}^{-3}\right)$

$D^{\circ} \quad$ diffusion coefficient at infinite dilution $\left(\mathrm{m}^{2} \mathrm{~s}^{-1}\right)$

$D \quad$ diffusion coefficient $\left(\mathrm{m}^{2} \mathrm{~s}^{-1}\right)$

$H \quad$ Henry's constant $(\mathrm{Pa})$

$M \quad$ molar weight $\left(\mathrm{g} \mathrm{mol}^{-1}\right)$

$p \quad$ partial pressure $(\mathrm{Pa})$

$P^{\text {sat }} \quad$ saturation pressure $(\mathrm{Pa})$

$Q_{\mathrm{g}} \quad$ gas flow rate $\left(\mathrm{m}^{3} \mathrm{~s}^{-1}\right)$

$T \quad$ absolute temperature (K)

$t \quad$ time (s)

$V_{\mathrm{L}} \quad$ absorbent volume $\left(\mathrm{m}^{3}\right)$

$x \quad$ molar fraction in liquid (-)

\section{Greek letters}

$\gamma \quad$ activity coefficient (-)

$\eta \quad$ dynamic viscosity (Pa s)

by the absorbent; (iv) no toxicity nor fire or explosion risks; (v) a low cost.

According to aforesaid criteria, several potential absorbents were investigated: vegetal oil [6], mineral oil [7], diesel oil [8], silicon oil [9-17], solar oil [14-15], polyglycols [13,16-25,27], alkylphthalates [26,28], alkyladipates [26]. Most of the studies were done in the last decade which illustrates the recent environmental concern and research for preserving air quality. These absorbents were selected according to specific advantages, for example a high absorption capacity, a good thermal stability or possibilities of reuse.

Literature review of previous papers on hydrophobic absorption have pointed out that it is impossible to compare the different investigated absorbents, due to a large heterogeneity in chosen pollutants, operating parameters and given results. Moreover, hydrophobic absorption still remains unused, because of overcoming disadvantages including high price, toxicity or high volatility.

The aim of this research work is to make hydrophobic absorption more competitive by selecting an efficient absorbent, studying efficiency and mass transfer in a packed column and the regeneration of the used absorbent. This paper presents the first results of the research: a detailed comparison and evaluation of different kinds of organic absorbents. Toluene was chosen as the target hydrophobic VOC because it is a toxic but common compound used in many industrial applications (printing, car painting, etc....) with a very low solubility in water [29]. The starting point of the investigation was a screening of commercially available components, with the requirement of being safe and cheap. The screening resulted in selection of four chemical classes (Fig. 1) (i) polyethylene glycols, commonly used in industry, (ii) phthalates, mainly used as plasticizers in PVC polymers, (iii) adipates, also used as plasticizers in paints and (iv) silicon oil, used in numerous industrial applications (anti foam, lubricant). Only solvents which present no toxicity risk and have a low vapor pressure were selected: polyethylene glycol 300 (PEG 300) and polyethylene 400 (PEG 400); polydimethylsiloxane (PDMS), usually named in the liquid form as silicon oil; di(2-ethylhexyl) adipate (DEHA); diisobutyl phthalate (DIBP); diisoheptyl phthalate (DIHP); diisodecyl phthalate (DIDP). No accurate data were found for viscosity and diffusion coefficients. Thermodynamic data about toluene equilibrium between gas phase and solute phase in selected absorbents were also unknown. Consequently, an experimental part was performed to check viscosity and thermodynamic equilibrium. Diffusion coefficients were estimated with the Scheibel equation [30], preferred to the Wilke-Chang equation for a better accuracy [31].

\section{Materials and methods}

\subsection{Viscosity}

Viscosity was measured with a cylindrical viscometer (AR 550, T.A. Instruments, France). A range of temperatures corresponding to usual temperatures was investigated. For each temperature, shear stress was plotted against shear velocity. The slope corresponds to the dynamic viscosity value $\eta$. Viscosity decreases with temperature, it is assumed that the behavior of Newtonian fluids follows the Guzman Andrade law:

$\eta=\exp \left(A+\frac{B}{T}\right)$

where $\eta$ is the dynamic viscosity, $T$ is the absolute temperature and $A, B$ are the Guzman Andrade coefficients.

\subsection{Toluene liquid-gas equilibrium}

Liquid-gas partitioning can be measured with several methods such as bubbling, volumetric, thin film and chromatographic methods [32]. Since bubbling method is done with a simple apparatus and allows to cover easily and with precision a large range of partial pressures, we chose to use this method. The bubbling lab-scale setup is shown on Fig. 2. The contaminated air was generated by injecting liquid toluene in a dry air stream (1). Flow rate of this stream is controlled by a mass flow meter (Brooks 5880 TR, Holland) (2) and set to $100 \mathrm{Lh}^{-1}$. Injection was done by

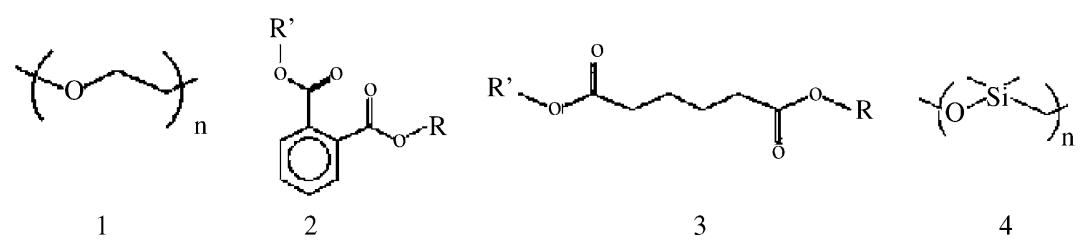

Fig. 1. Selected chemical families: (1) polyethylene glycol; (2) phthalates; (3) adipates; (4) silicon oil. 


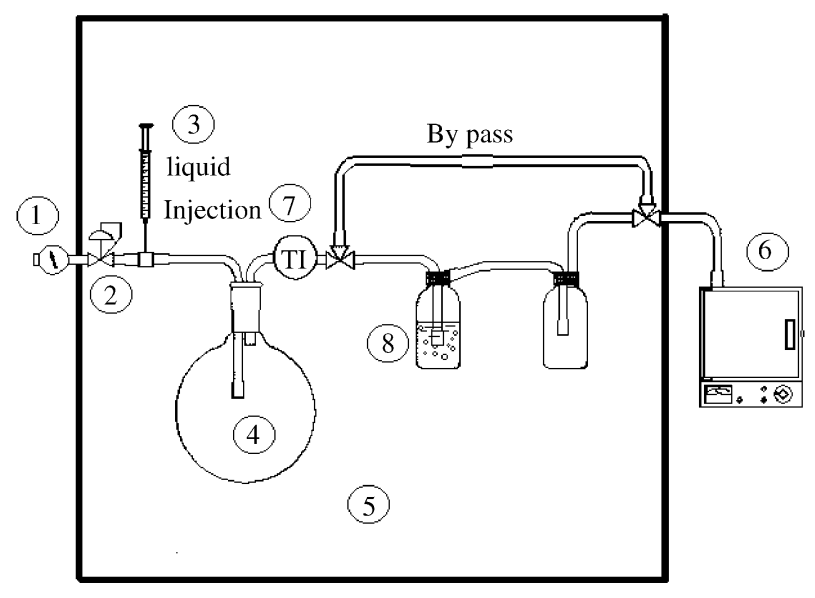

Fig. 2. Bubbling plant.

means of a syringe dispenser (3) (Précidor, France), according to the target gas concentrations range: $C_{\mathrm{G}, \text { in }}=0.37-3.7 \mathrm{~g} \mathrm{~m}^{-3}$. The loaded stream flowed in a buffer volume (4) to homogenize the gas concentration then through a porous head in the absorbent solution. The whole system was put into a thermal regulation box $\left(25^{\circ} \mathrm{C}\right)(5)$. Incoming and outgoing gases were analyzed by a Flame-Ionization Detector FID (COSMA Graphite 730, France) (6), and their temperatures were measured (7). Each experiment was performed as following: bubbler (8) was filled with about $150 \mathrm{~mL}$ of absorbent; the exact volume was known by measuring the real mass introduced and converted by the knowledge of the density. After $1 \mathrm{~h}$, the temperature of the liquid was measured to control its $25^{\circ} \mathrm{C}$ value. Dry air and toluene injection flow rates were set to the wanted value. This loaded gas then flowed through the by pass to prevent polluting the introduced pure absorbent. Outgoing gas was analyzed by FID and its temperature was controlled. When both temperature and concentration were stable, valves were switched and air flowed through the bubbling vessel. Outgoing gas concentration was followed until absorbent saturation, which corresponded to a gas concentration equal to the incoming gas composition and stable in time. For a semi batch reactor, the mass balance is:

$Q_{\mathrm{g}} C_{\mathrm{g}, \text { in }}=Q_{\mathrm{g}} C_{\mathrm{g}, \text { out }}(t)+V_{\mathrm{L}} \frac{\mathrm{d} C_{\mathrm{L}}(t)}{\mathrm{d} t}$

where $Q_{\mathrm{g}}$ is the flow rate, $V_{\mathrm{L}}$ is the absorbent volume, $C_{\mathrm{g}, \text { in }}$ and $C_{\mathrm{g}, \text { out }}$ are the inlet and outlet concentration of toluene in the gas flow. The concentration of toluene in the liquid phase $C_{\mathrm{L}}(t)$ can be expressed by:

$C_{\mathrm{L}}(t)=\frac{Q_{\mathrm{g}}}{V_{\mathrm{L}}}\left(C_{\mathrm{g}, \text { in }} t-\int C_{\mathrm{g}, \text { out }}(t) \mathrm{d} t\right)$.

The quantity of no absorbed toluene is given by the integral term and calculated by a numerical integration. Results allow to calculate the variation of the toluene concentration in the liquid phase as a function of time. The limit value is the saturation concentration $C_{\mathrm{s}}$.

The vapor liquid equilibrium (VLE) can be expressed in terms of variation of partial pressure of the component $p$ with its mole fraction $x$ in the solvent phase. By assuming that the gas phase is perfect, Henry's law constant $H$ can be defined from the following limit:

$H=\lim _{x \rightarrow 0} \frac{p}{x}$.

The activity coefficient $\gamma$ is defined by the following equation:

$p=\gamma x P^{\mathrm{sat}}$

where $P^{\text {sat }}$ is the saturation pressure of the component. This value was found in literature for toluene at $25^{\circ} \mathrm{C}: P^{\mathrm{sat}}=3803 \mathrm{~Pa}$ ). Henry's constant $H$ and activity coefficient $\gamma$ are then linked as following:

$\gamma=\frac{H}{P^{\text {sat }}}$.

\section{Results and discussion}

\subsection{Viscosity}

Viscosity of an absorbent strongly influences mass transfer kinetics from diffusion and hydrodynamic points of view: a low viscosity minimizes thickness of the interface layer on the liquid side and increases diffusion kinetics in this layer.

Fig. 3 shows that all solvents present a Newtonian behavior at $20^{\circ} \mathrm{C}$ (linearity of shear stress $\sigma$ against shear velocity $\gamma)$. The corresponding values of viscosity are given on Table 1 . Viscosities were also measured at $30,40,50$ and $60^{\circ} \mathrm{C}$. The collected data permit to calculate the two parameters in the Guzman Andrade viscosity equation. Table 1 gives the obtained values for A and B. A good agreement was observed between data and the equation.

As expected, molecules with a high molar mass like PEG 400, PEG 300 and DIDP present the highest viscosity. But this trend is not respected while comparing phthalates and polyglycols classes: DIDP presents a lower viscosity than PEG 400, and DIHP presents a lower viscosity than PEG 300 although molar mass of phtalates higher is. Stronger intermolecular interactions

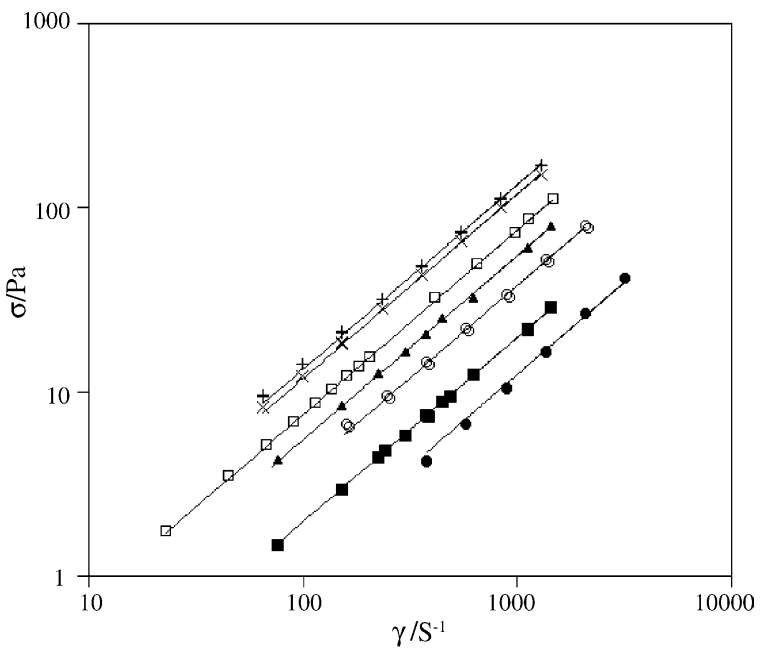

Fig. 3. Rheology of selected solvents $\left(20^{\circ} \mathrm{C}\right)$ : (+) PEG 400; $(\times)$ DIDP; $(\bigcirc)$

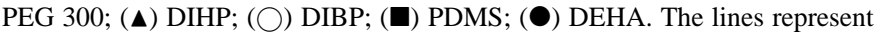
the regression fit. 
Table 1

Dynamic viscosity $\eta\left(20^{\circ} \mathrm{C}\right)$ and Guzman Andrade parameters $A, B$

\begin{tabular}{|c|c|c|c|c|c|}
\hline \multirow[t]{2}{*}{ Symbol } & \multirow[t]{2}{*}{$\eta(\mathrm{Pas})$} & \multirow[t]{2}{*}{$R^{2}$} & \multicolumn{3}{|c|}{ Guzman Andrade modelization } \\
\hline & & & $A(-)$ & $B(\mathrm{~K})$ & $R^{2}$ \\
\hline PEG 300 & 0.0755 & 0.9998 & $1.36 \times 10^{-7}$ & 3930 & 0.994 \\
\hline PEG 400 & 0.1336 & 0.9997 & $1.84 \times 10^{-9}$ & 5271 & 0.983 \\
\hline DIBP & 0.0378 & 0.9999 & $1.11 \times 10^{-8}$ & 4420 & 0.985 \\
\hline DIHP & 0.0550 & 0.9992 & $5.14 \times 10^{-8}$ & 4146 & 0.999 \\
\hline DIDP & 0.1188 & 0.9997 & $2.70 \times 10^{-10}$ & 5847 & 0.990 \\
\hline DEHA & 0.0125 & 0.9962 & $1.12 \times 10^{-6}$ & 2748 & 0.999 \\
\hline SO & 0.0198 & 0.9995 & $6.93 \times 10^{-4}$ & 973 & 0.999 \\
\hline
\end{tabular}

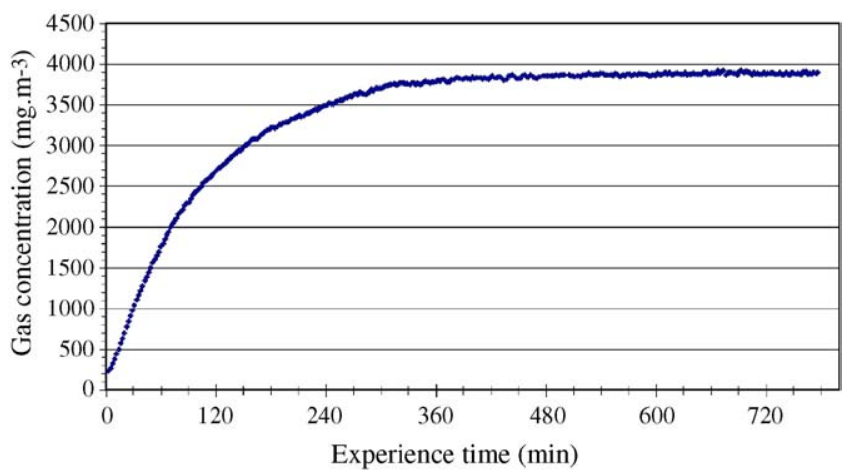

Fig. 4. Gas concentration at the outlet of bubbler (silicon oil, toluene concentration $=3.7 \mathrm{~g} \mathrm{~m}^{-3}$ ).

should explain this observation. DEHA and silicon oil present the lowest viscosities over all experimented liquids, more than 10 times lower than PEG 400. As a consequence, DEHA and silicon oil seem the most interesting liquids to be used in an absorption process.

\subsection{Thermodynamic equilibrium of toluene between gas phase and solute phase}

An example of experimental data about gas concentration of toluene at the outlet of the bubbler is given (Fig. 4), and the liquid concentration of toluene was calculated (Fig. 5). Saturation concentrations values were calculated as indicated in part 2 and are reported in Table 2. Repetition experiments (five runs) gave

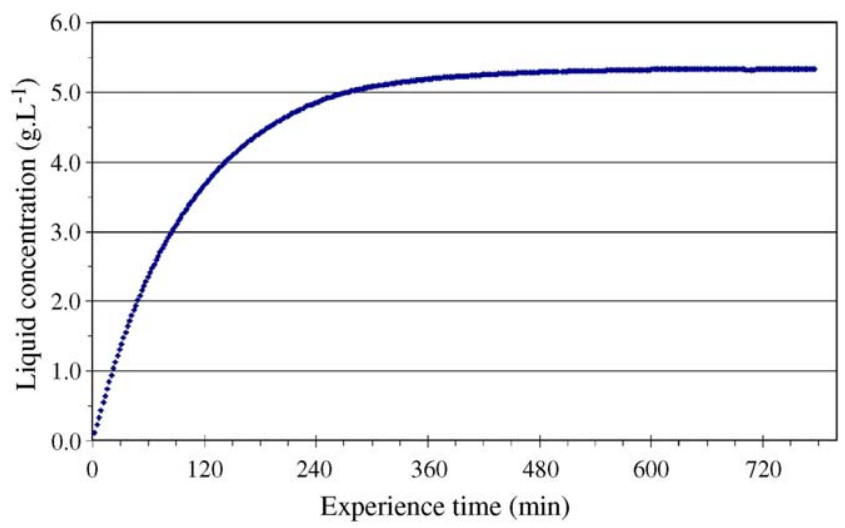

Fig. 5. Toluene concentration in liquid (silicon oil, toluene concentration $=3.7 \mathrm{~g} \mathrm{~m}^{-3}$ ).
Table 2

Saturation concentrations $C_{\mathrm{s}}\left(25^{\circ} \mathrm{C}\right)$ for different toluene concentrations in air

\begin{tabular}{llllllrr}
\hline$C_{\mathrm{g}, \text { in }}\left(\mathrm{g} \mathrm{m}^{-3}\right)$ & \multicolumn{2}{l}{$C_{\mathrm{s}}\left(\mathrm{g} \mathrm{L}^{-1}\right)$} & & & & \\
\cline { 2 - 7 } & PDMS & PEG 300 & PEG 400 & DIDP & DIHP & DIBP & DEHA \\
\hline 0.38 & 0.39 & 0.47 & 0.63 & 1.05 & 1.07 & 1.09 & 1.06 \\
1.85 & 2.67 & 2.25 & 2.86 & 4.01 & 5.08 & 5.13 & 5.71 \\
3.70 & 5.31 & 4.22 & 6.80 & 8.40 & 9.06 & 10.60 & 13.20
\end{tabular}

Table 3

Henry's constant $H$ and activity coefficient $\gamma$ values at $25^{\circ} \mathrm{C}$

\begin{tabular}{llllllll}
\hline Absorbent & PDMS & PEG 300 & PEG 400 & DIDP & DIHP & DIBP & DEHA \\
\hline$H(\mathrm{kPa})$ & 5.56 & 8.15 & 4.01 & 2.47 & 2.77 & 3.35 & 1.98 \\
$\gamma(-)$ & 1.46 & 2.13 & 1.20 & 0.64 & 0.75 & 0.88 & 0.50 \\
\hline
\end{tabular}

a standard deviation $\sigma=0.09 \mathrm{~g} \mathrm{~L}^{-1}$ and the accuracy was determined as equal to $2 \%$. Three levels of toluene concentration in gas were investigated: $0.38,1.85$ and $3.70 \mathrm{~g} \mathrm{~m}^{-3}$.

Eqs. (4) and (6) were used to calculate equilibrium constants $H$ and $\gamma$ (Table 3 ). This $H$ value has an explicit interest in air treatment consideration. Indeed, for a given gas phase, $H$ value gives the composition of the liquid which would be in thermodynamic balance with the entering air. $\gamma$ is characteristic of the interaction

Table 4

Comparative chart of activity coefficients $\gamma$ with literature

\begin{tabular}{lrrl}
\hline Solvent & $M\left(\mathrm{~g} \mathrm{~mol}^{-1}\right)$ & $\gamma(-)$ & Author \\
\hline Polyethylene glycol 300 & 300 & 2.14 & This work \\
Polyethylene glycol 400 & 400 & 1.05 & This work \\
Diethyl phtalate & 2220 & 1.22 & Alessi et al. [34] \\
Di- $n$-butyl phthalate & 278 & 0.70 & Alessi et al. [34] \\
Diisobutyl phthalate & 278 & 0.97 & Alessi et al. [34] \\
& 278 & 0.88 & This work \\
Dicyclohexyl phthalate & 330 & 0.82 & Alessi et al. [34] \\
Diisoheptyl phthalate & 362 & 0.73 & This work \\
Di (2-ethylhexyl) phthalate & 390 & 0.75 & Alessi et al. [34] \\
Di (2-ethylhexyl) adipate & 351 & 0.52 & This work \\
Diisodecyl phthalate & 446 & 0.64 & Alessi et al. [34] \\
& 447 & 0.65 & This work \\
Butyl benzyl phthalate & 364 & 0.99 & Alessi et al. [34] \\
Butyl ethylhexyl phthalate & 331 & 0.70 & Alessi et al. [34] \\
Paratherm & 350 & $10.30^{\mathrm{a}}$ & Poddar and Sirkar [7] \\
Silicon oil & 300 & $6.99^{\mathrm{a}}$ & Poddar and Sirkar [7] \\
\hline
\end{tabular}

\footnotetext{
${ }^{\text {a }}$ Calculated from Henry's law coefficient given by the authors.
} 
Table 5

Recapitulative chart of absorbent properties: Henry's constant $H$, viscosity $\eta$, diffusion coefficient at infinite dilution $D^{\circ}$, vapor pressure $P^{\text {sat }}$

\begin{tabular}{|c|c|c|c|c|c|}
\hline Chemical family & Absorbent & $H(\mathrm{kPa})\left(25^{\circ} \mathrm{C}\right)$ & $\eta(\mathrm{Pas})\left(20^{\circ} \mathrm{C}\right)$ & $D^{\circ}\left(10^{-10} \mathrm{~m}^{2} \mathrm{~s}^{-1}\right)\left(25^{\circ} \mathrm{C}\right)$ & $P^{\mathrm{sat}}(\mathrm{mPa})\left(20^{\circ} \mathrm{C}\right)$ \\
\hline \multirow{2}{*}{ Polyethylene glycols } & PEG 300 & 8.15 & 0.0755 & 0.81 & $<10^{2}$ \\
\hline & PEG 400 & 4.01 & 0.1336 & 1.43 & $<10^{2}$ \\
\hline \multirow{3}{*}{ Phthalates } & DIBP & 3.35 & 0.0378 & 2.86 & $<0.1$ \\
\hline & DIHP & 2.77 & 0.0550 & 1.97 & $<0.001$ \\
\hline & DIDP & 2.47 & 0.1188 & 0.91 & $<0.0001$ \\
\hline Adipates & DEHA & 1.98 & 0.0125 & 8.65 & $<0.01$ \\
\hline Silicon oils & PDMS & 5.56 & 0.0198 & 5.46 & $<0.133$ \\
\hline
\end{tabular}

between toluene and the absorbent. A $\gamma$ value lower than the unity translates a more favorable thermodynamic equilibrium than the case of an ideal solution without interactions.

As expected, the tested solvents present considerably high absorption capacity. As comparison, Nielsen [33] evaluated Henry constant of toluene with water such as $H$ equals $53 \times 10^{3} \mathrm{kPa}$. Results show that phtalates and adipate have greater trapping capacities than polyethylene glycols and silicon oil. This is confirmed by the low activity coefficients values. Toluene absorption capacities for phthalates are close to the one of DEHA although phthalates are based on an aromatic ring. This aromatic ring does not seem to play a strong role in toluene solvation mechanism. Polyethylene glycols show interesting absorption capacities despite the value is close to the half of the previously discussed solvents. PEG 400 and PEG 300 are based on the same monomer scheme but reveal different absorption capacities. Silicon oil shows the lowest absorption capacity of all tested solvents.

Comparison with data from other authors is presented in Table 4. Alessi et al. [34] used a headspace chromatographic method to evaluate activity coefficient of toluene in different phthalates. Poddar and Sirkar [7] gave Henry's law constants with silicon oil and a commercial heating oil, Paratherm with which one it was possible to calculate the activity coefficients. Our data are close to values proposed by Alessi et al. [34] about DIDP and DIBP, which validates our experimental method.

Finally, an overall examination of the experimental and collected data shows that di(2-ethylhexyl) adipate presents an activity coefficient significantly lower than the other solvents and should be very interesting in toluene absorption.

\subsection{Diffusion coefficients}

Diffusion coefficients at infinite dilution $D^{\circ}$ correspond in the hypothetic state of a specie which will diffuse at infinite dilution. It is assumed that mass transfer increases with the diffusion coefficient, that is why diffusion coefficient plays a strong influence on absorption efficiency. Values were calculated by the Scheibel equation and are reported on Table 5. Viscosity influences strongly diffusion coefficient, therefore DEHA and silicon oil present the highest values.

\subsection{Economical criteria}

Economical criteria have to be taken into account in order to select the more suitable solvent in an absorption purpose. Cost of absorbent is mainly important at the investment stage, since the absorbent is supposed to be regenerated and so no adding of new solvent is requested. Solvents were chosen from industrial and commonly used components. Prices of most studied solvents are less than \$3 US per liter. All solvents are on the same price, except for silicon oil: it appears that silicon oil is approximately six times more expensive than the other solvents.

\subsection{Choice of the solvent}

A recapitulative chart of experimental and collected data is given on Table 5. DEHA appears clearly to be better absorbent than others as it has high capacity of toluene absorption, low viscosity, low vapor pressure and high diffusion coefficient for toluene. Polyethylene glycols were previously studied in VOC absorption but are definitively not that good due to lower absorption capacity and a higher viscosity.

Table 6 gives activity coefficient of toluene in DEHA at 20, 35 and $70^{\circ} \mathrm{C}$. Henry's law dependence on temperature can be expressed as:

$\ln H=a+\frac{b}{T}$

where $a$ and $b$ are regression coefficients. $a$ was found equal to -5772 and $b$ equal to $26.925 \mathrm{~K}$. Determination coefficient $R^{2}$ was equal to 0.9992 on the range $T=20-70{ }^{\circ} \mathrm{C}$.

Table 6

Activity coefficient $\gamma$ of toluene in DEHA at other temperatures, and for different VOCs

\begin{tabular}{llll}
\hline VOC & $T\left({ }^{\circ} \mathrm{C}\right)$ & $\gamma(-)$ & Author \\
\hline & 20 & 0.44 & This work \\
Toluene & 25 & 0.52 & This work \\
& 35 & 0.55 & Weisweiler and Winterbauer [26] \\
Chlorobenzene & 35 & 0.49 & Weisweiler and Winterbauer [26] \\
Benzene & 35 & 0.53 & Weisweiler and Winterbauer [26] \\
$o$-Xylene & 35 & 0.60 & Weisweiler and Winterbauer [26] \\
$p$-Xylene & 35 & 0.61 & Weisweiler and Winterbauer [26] \\
$m$-Xylene & 35 & 0.68 & Weisweiler and Winterbauer [26] \\
Ethylbenzene & 35 & 0.70 & Weisweiler and Winterbauer [26] \\
Cyclohexane & 35 & 0.71 & Weisweiler and Winterbauer [26] \\
$n$-Hexane & 35 & 0.76 & Weisweiler and Winterbauer [26] \\
Dichloromethane & 30 & 0.30 & Hadjoudj et al. [35] \\
Tetrachloroethane & 30 & 0.69 & Hadjoudj et al. [35] \\
\hline
\end{tabular}


Previous authors [26,35] studied VLE of DEHA with other VOCs (Table 6). Results show that DEHA presents good trapping behavior for other aromatics $\left(\gamma_{\text {benzene }}=0.53\right.$; $\left.\gamma_{\text {xylenes }}<0.68 ; \gamma_{\text {ethylbenzene }}=0.70\right)$ and for chlorinated VOCs $\left(\left(\gamma_{\text {dichloromethane }}=0.30 ; \gamma_{\text {tetracholoethane }}=0.69 ; \gamma_{\text {chlorobenzene }}=\right.\right.$ $0.49)$.

\section{Conclusions and perspectives}

This paper aimed to review hydrophobic absorption knowledge, and by a methodic way and a pure industrial purpose to determine an efficient absorbent. All missing experimental data were determined, and this allowed selection of di(2-ethylhexyl) adipate (DEHA) as the most attractive absorbent. Influence of temperature was correlated in the range $20-70^{\circ} \mathrm{C}$. DEHA was shown to be efficient in other aromatic and chlorinated VOCs.

Regeneration of used solvent is the major point not presented in this study. It is nevertheless the determinant point to develop hydrophobic absorption in industrial treatment of VOC loaded air. As said by Poddar and co-workers [36,37] and Majumdar et al. [11], regeneration of the solvent can be achieved by a membrane based technology: pervaporation. This process allows organic separations with low fluxes but high selectivity. This could perfectly solve the problem of the used absorbent regeneration, thus enabling the use of absorption process to the hydrophobic air treatment field. Further studies will focus on this point, and will characterize the mass transfer kinetics in a packed column.

\section{Acknowledgements}

This work was accomplished with the financial support of ADEME (Agence de l'Environnement et de la Maitrise de l'Energie, France) and the Europe Environnement company (Vieux Thann, France).

\section{References}

[1] National Air Quality and Emissions Trends Report, EPA, USA, 1998.

[2] European Community Parliament, 1999/13/CE Directive, march 11th 1999. 2001/81/CE Directive, 23rd October, 2001.

[3] P. Le Cloirec, Les composés organiques volatils (COV) dans l'environnement, Lavoisier, Paris, 1998.

[4] E. Dumont, Mass transfer enhancement of gas absorption in oil-water systems: a review, Chem. Eng. Proc. 42 (2003) 419-438.

[5] J. Samak, Lavage de gaz chargés en COV hydrophobes par une suspension de charbon actif dans l'eau, Thèse, Université de Pau et des Pays de L'adour, France, 2002.

[6] S. Pierucci, R. Del Rosso, D. Bombardi, A. Concu, G. Lugli, An innovative sustainable process for VOCs recovery from spray paint booths, Energy J. 30 (2005) 1377-1386.

[7] T.K. Poddar, K.K. Sirkar, Henry's law constant for selected volatile organic compounds in high-boiling oils, J. Chem. Eng. Data 41 (1996) $1329-1332$.

[8] J.V. De Assuncao, S.M.F. Vasconcelos, Control of toluene and xylene bu absorption in mineral oil, in: Proceedings of Air and Waste Management Association's 90th annual meeting and exhibition, Toronto, 1997.
[9] A. Azou, Réduction des émissions atmosphériques de composés organiques volatils: absorption, adsorption, régénération in situ, Thèse, Université de Rennes I, France, 1991.

[10] B. Xia, S. Majumdar, K.K. Sirkar, Regenerative oil scrubbing of volatile organic compounds from a gas stream in hollow fiber membrane device, Ind. Eng. Chem. Res. 38 (1999) 3462-3472.

[11] S. Majumdar, D. Bhaumik, K.K. Sirkar, G. Simes, A pilot-scale demonstration of a membrane based absorption stripping process for removal and recovery of volatile organic compounds, Environ. Prog. 20 (2001) 27-34.

[12] A. De Guardia, A. Bouzaza, G. Martin, A. Laplanche, Procédé d'épuration de gaz contenant des COV soufrés par lavage à l'huile et oxydation à l'ozone des polluants absorbés, Pollut. Atmos. 38 (1996) 82-92.

[13] A. Kalina, H. Wanko, S. Weiss, Untersuchung zum Einfluss des Wasserdampfs auf die Absorption organischer Komponenten mit hochsiedenden Waschflüssigkeiten, Chem. Tech. (1994) 1-62.

[14] N.I. Volodin, V.M. Puzyreva, V.E. Soroko, Absorption treatment of gases to remove impurities of organic solvents, Russ. J. Appl. Chem. 70 (1997) $1745-1747$

[15] N.I. Volodin, V.M. Puzyreva, V.E. Soroko, On the problem of extraction of organic solvents from saturated absorbent, Russ. J. Appl. Chem. 70 (1997) 1985-1986.

[16] A. Schmidt, M. Ulrich, Absorptionsmittel zur Reinigung löesemittelhaltiger Abluft, Chem. Ing. Tech. 62 (1990) 43-46.

[17] A. Armand, H.G. Uddholm, P.T. Vikström, Absorption method to clean solvent-contaminated process aie, Ind. Eng. Chem. Res. 29 (1990).

[18] F. Cotte, J.-L. Fanlo, P. Le Cloirec, P. Escobar, absorption of odorous molecules in aqueous solutions of polyethylene glycols, Environ. Technol. 16 (1995) 127-136.

[19] K.E. Porter, S. Sitthiosoth, J.D. Jenkins, Designing a solvent for gas absorption, Trans IChemE 69 (1991) 229-236.

[20] N.J. Stockley, VOC abatement by absorption, Eur. Coat. J. (1994) 751-757.

[21] U. Block, Abgaswäsche mit organischen Waschflüssigkeinten und Wasser, Staub Reinhaltung Luft 36 (1976) 348-353.

[22] X. Wang, R. Daniels, R.W. Baker, Recovery of VOCs from high-volume, low-VOC-concentration air streams, AIChE J. 47 (2001) 1094-1100.

[23] K. Geisthardt, J. Holtze, R. Ludwig, T. Pilhofer, Absorption process for the removal of organic solvents from exhaust air, Chem. Eng. Technol. 12 (1989) 63-70.

[24] L.E. Gearhart, New glycol-unit design achieves VOC, BTEX reductions, Oil Gas J. (1998) 61-64.

[25] W. Müller, Absorption organischer Lösemittel mit Glykolethern, VDI Berichte (1989) 373-394.

[26] W. Weisweiler, H. Winterbauer, Alternatives Auswahlkriterium für Waschflüssigkeiten zur Absorption flüchtiger organischer Verbindungen, Staub Reinhaltung Luft 55 (1995) 221-228.

[27] S. Zwerver, R.S.A.R. Van Rompaey, M.T.J. Kok, M.M. Berk, Climate change research: evaluation and policy implications, Elsevier Science, 1995, 1093-1104.

[28] M. Duss, P. Bomio, Rückgewinnung organisher Dämpfe aus Abgasströmen mit Absorptionsverfahren, Chem. Ing. Tech. 63 (1991) 388-389.

[29] F. Cotte, Absorption en colonne garnie et en tour à atomisation. Application au traitement de composés organiques volatils, Thèse, Université de Pau et des Pays de l'Adour, France, 1996.

[30] W.Y. Fei, H.-J. Bart, Predicting diffusivities in liquids by the group contribution method, Chem. Eng. Proc. 40 (2001) 531-535.

[31] B.E. Poling, J.M. Prausnitz, J. O'Connell, The Properties of Gases and Liquids, McGraw Hill, New York, 2000.

[32] P.G.T. Fogg, W. Gerrard, Solubility of Gases in Liquids, Wiley Sons, Chichester, England, 1991

[33] F. Nielsen, E. Olsen, A. Fredenslund, Henry's law constants and infinite dilution activity coefficient for volatile organic compounds in water by a validated batch air stripping method, Environ. Sci. Technol. 28 (1994) 2133-2138. 
[34] P. Alessi, I. Kikic, G. Torriano, Activity coefficients of hydrocarbons in phthalates, J. Chromatogr. 105 (1975) 257-264.

[35] R. Hadjoudj, H. Monnier, F. Lapicque, C. Roizard, Absorption of chlorinated VOCs in high-boiling solvents: Determination of Henry's Law, Ind. Eng. Chem. Res. 43 (2004) 2238-2246.
[36] T.K. Poddar, Membrane-based absorption of VOCs from a gas stream, AIChE J. 42 (1996) 3267-3282.

[37] T.K. Poddar, S. Majumdar, K.K. Sirkar, Removal of VOCs from air by membrane-based absorption and stripping, J. Membr. Sci. 120 (1996) 221-237. 